Arq. Bras. Med. Vet. Zootec., v.67, n.1, p.309-314, 2015

\title{
Identificação espécie-específica de carnes e produtos cárneos de origem bubalina e bovina pela técnica de PCR-RFLP
}

\author{
[Species-specific identification of red-meat and meat derivative \\ products with the PCR-RFLP technique] \\ L.V. Teixeira, C.S. Teixeira, D.A.A. Oliveira \\ Escola de Veterinária - Universidade Federal de Minas Gerais - UFMG - Belo Horizonte, MG
}

\section{RESUMO}

Para avaliar a viabilidade da metodologia da Reação em Cadeia da Polimerase associada com o Polimorfismo de Fragmentos de DNA (PCR-RFLP) na identificação de fraude intencional e contaminação acidental em produtos cárneos de origem bubalina, in natura e processados, foram testadas amostras puras e amostras de carnes com misturas controladas, produzidas em laboratório, com adição de $1 \%, 5 \%, 10 \%$ e $50 \%$ de carne bovina em carne de búfalo, homogeneizada crua e em amostras autoclavada. Foram comparados, ainda, diferentes métodos de extração, usando um kit comercial e a técnica clássica, utilizando fenol/clorofórmio. O resultado estatístico foi obtido por tabela de contingência, analisada pelo teste do qui-quadrado $\left(\chi^{2}\right)$ e do exato de Fisher. A especificidade encontrada foi altamente significativa $(\mathrm{P}<0,0001)$. Observou-se também sensibilidade altamente significativa nas diluições a partir de $10 \%(\mathrm{P}<0,0001)$. A técnica tem alta especificidade e sensibilidade para detectar até mesmo contaminação de $1 \%$, mas a repetibilidade desse resultado impede a aplicação oficial desse método para a inspeção de contaminação acidental, sendo recomendada somente para inspeção de fraude a partir de $10 \%$ de substituição. Em carnes autoclavadas, a eficácia do teste é menor. A técnica pode ser empregada para certificação de produto específico (selo de identidade de espécie).

Palavras-chave: Bostaurus, Bubalusbubalis, carne, fraude, certificação

\begin{abstract}
The present study aimed at evaluate the viability of PCR-RFLP (Polymerase Chain Reaction - Restriction Fragment Length Polymorphism) for identification of fraud and/or accidental contamination in buffalo meat - fresh and processed. Pure, autoclaved and controlled fraud samples, produced in the laboratory with the addition of 1, 5, 10 and 50\% of beef in raw homogenized buffalo meat samples, were tested. Furthermore, different extraction methods, using a commercial kit and classical technique using phenolchloroform, were compared. The statistical result was obtained by contingency table analyzed by chisquare and the Fisher exact test. The specificity was highly significant ( $p<0.0001)$, and the sensitivity was highly significant in dilutions from 10\% ( $p<0.0001)$. Despite its accuracy and precision, capable to detect a contamination level of 1\%, PCR-RFLP technique is not recommended for inspection in cases of accidental contamination. This is due to the need of test repetition in levels of contamination lower than 10\%. The efficiency of this test is lower to autoclaved meat. The PCR-RFPL technique can be used for certification of food made with specific species (species identification certification stamp).
\end{abstract}

Keywords: Bos Taurus, Bubalusbubalis, meat, fraud, certification

\section{INTRODUÇÃO}

A alta qualidade nutricional e sensorial da carne de búfalo tem levado um aumento no seu consumo em várias partes do mundo. A carne

Recebido em 19 de setembro de 2013

Aceito em 10 de setembro de 2014

E-mail: viana.lilian@gmail.com bubalina apresenta aspectos nutricionais e sensoriais superiores quando comparada à carne bovina, porém as duas espécies apresentam rendimento de carcaça semelhante. Contudo, a garantia ao consumidor de que o produto é realmente derivado exclusivamente de carne 
bubalina só é possível com a certificação por meio de selo de garantia obtido após análise laboratorial acurada.

A autenticidade e a garantia de origem dos produtos alimentícios são critérios de qualidade de grande importância para os consumidores e têm incentivado a adoção de políticas governamentais visando à proteção da cadeia de produção de alimentos. A adulteração de produtos cárneos não apenas constitui fraude econômica, mas também está relacionada a problemas de tabus religiosos, aversões de cunho moral ou alergias a espécies particulares de carne (Gouli et al., 1999; Tanabe et al., 2007; DAFM, 2013). Dessa maneira, a identificação e a diferenciação de carnes das diferentes espécies visam, sobretudo, coibir a possibilidade de fraude e falsificação, quando a carne da espécie animal anunciada é substituída por outra de pior qualidade. Desse modo, são necessárias metodologias adequadas para a detecção de ingredientes de origem animal nos alimentos e a identificação de sua espécie originária (Corona et al., 2007; Kesmen et al., 2007; Lopparelli et al., 2007; Zhang et al., 2007).

As técnicas utilizadas para a identificação de carnes de diferentes espécies animais são a microscopia óptica clássica, a eletroforese, os imunoensaios (ELISA e ORBIT) e cromatografia líquida de alto desempenho (HPLC). O inconveniente é que, na identificação de espécies filogeneticamente próximas, como o búfalo e o bovino, essas técnicas nem sempre permitem visualização e identificação satisfatórias. O aquecimento da carne também prejudica a utilização dessas metodologias, principalmente dos imunoensaios, pois o processamento térmico pode destruir os epítopos, inviabilizando a ligação antígeno-anticorpo (Herman, 2001; Bellis et al., 2003; Lopez-Calleja et al., 2005; Mayer, 2005).

Técnicas de biologia molecular, que utilizam o DNA, oferecem a possibilidade de detectar ingredientes de origem animal em alimentos e identificar de quais espécies são originários. Em relação à carne, esse método é eficaz tanto em matéria crua, como também em produtos fermentados, cozidos ou autoclavados. A metodologia da Reação em Cadeia da Polimerase associada com o Polimorfismo de Fragmentos de
DNA (PCR-RFLP) tem sido amplamente utilizada para a diferenciação espécie específica, pois um único par de primers produz um fragmento que pode identificar múltiplas espécies por meio da utilização de enzimas de restrição apropriadas. Essa característica faz desta uma técnica de boa aplicabilidade e com custo mais baixo quando comparada a outras técnicas moleculares (Lockley e Bardsley, 2000; Ballin et al., 2009; Kesmlen et al., 2009; Bottero e Dalmasso, 2010).

Com base nesses aspectos, o objetivo deste trabalho foi avaliar a sensibilidade, especificidade e aplicabilidade da técnica de PCR-RFLP para diferenciação de carnes bubalina e bovina em produtos crus e submetidos a tratamento térmico.

\section{MATERIAL E MÉTODOS}

Foram coletadas amostras dos músculos masseter e pterigoides de 60 animais, sendo 30 bovinos (Bos taurus taurus e Bos taurus indicus) e 30 bubalinos (Bubalus bubalis), provenientes de abatedouros sob inspeção veterinária oficial. Também foram coletadas amostras de pelos (bulbo piloso) dos mesmos animais para utilização como controle positivo de amplificação e tamanho de fragmento de cada espécie.

Para avaliar a capacidade do método em detectar contaminações acidentais ou fraudes por substituição de carnes de uma espécie por outra, amostras de carne bubalina foram adicionadas de $1 \%, 5 \%, 10 \%$ e $50 \%$ de carne bovina, sendo cada par formado pela associação da carne de um indivíduo bubalino e um indivíduo bovino, totalizando no mínimo 30 repetições para cada nível de adição de carne bovina pesquisado. As misturas foram homogeneizadas em cadinho de porcelana. Foram testadas, também, 30 amostras de carnes autoclavadas $\left(120^{\circ} \mathrm{C}\right.$, por 20 minutos), de búfalos e de bovinos, para avaliar a capacidade do método de detectar fraude em produtos processados termicamente.

Após testar dois métodos de extração de DNA em 10 amostras de carne, sendo o primeiro método o que utiliza fenol/clorofórmio (Sambrook et al., 1989) e o segundo utilizando o kit comercial EZ-DNA, conforme instruções do 
fabricante (Biological Industries, Kibbutz Beit Haemek, Israel), sendo o primeiro o que obteve melhor resultado. Com isso, o DNA das 30 amostras de carnes bovina e bubalina e de todas as amostras de carne de búfalo adicionadas de carne bovina $(1 \%, 5 \%, 10 \%$ e $50 \%)$ foi extraído, após digestão com proteinase $\mathrm{K}$, utilizando-se a metodologia do fenol/ clorofórmio/álcool-isoamílico e precipitação e purificação com etanol.

Para a amplificação por PCR, foram empregados iniciadores universais de citocromo $b$ de artiodátilos, o que dispensa a necessidade de controle interno para monitorar a amplificação de DNA, conforme demonstrado por Partis et al. (2000). Foram utilizados iniciadores modificados por Verkaar et al. (2002) para amplificar fragmentos de DNA de 271 pares de base (pb), e o sistema de amplificação da PCR utilizado foi adaptado do protocolo descrito por esses mesmos autores, com reação contendo $5 \mathrm{mM}$ de cada iniciador, $0,2 \mathrm{mM}$ de cada dNTP 2 unidades de TaqDNApolimerase, $1 \mathrm{X}$ de tampão (Tris $\mathrm{HCl}$ $10 \mathrm{mM} ; 15 \mathrm{mM} \mathrm{MgCl}_{2}$. $50 \mathrm{mM} \mathrm{KCl}$ ), $10 \mathrm{ng}$ de DNA amostral e água ultrapura autoclavada (Merck Millipore, Darmstadt, Alemanha), perfazendo um total de $20 \mu \mathrm{L}$.

Foi feita análise de restrição de endonuclease dos produtos da PCR com TaqI (TłGGA AGC $\uparrow$ T) para detecção da espécie bubalina e com HinfI

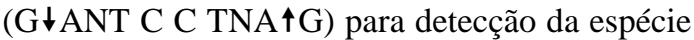
bovina. Foram acrescidos $5 \mu \mathrm{L}$ de tampão e $10 \mathrm{U}$ de enzima de restrição (Invitrogen, Carlsbad, CA, USA) aos produtos da PCR, que foram submetidos a 3 horas de digestão a $65^{\circ} \mathrm{C}$ para a TaqI e a $37^{\circ} \mathrm{C}$ para a HinfI.

Os produtos da restrição foram diluídos em solução de tampão de corrida $2 X$ e, então, submetidos à corrida eletroforética (200 Volts, $30 \mathrm{~mA}$ por 2 horas), juntamente com o padrão de peso molecular pGEM® (Promega, Madison, WI, USA), em gel de poliacrilamida $8 \%$. Foram incluídos um controle positivo (bulbo piloso) de búfalo e de bovino, um controle negativo (produto de PCR sem adição de enzimas) e um branco (solução de reação, com adição de enzimas e sem adição de DNA). A visualização dos produtos, tanto após PCR quanto após digestão, se deu pela coloração dos géis com nitrato de prata.

O experimento foi conduzido em um delineamento inteiramente ao acaso, utilizando carne de duas espécies (bubalina e bovina) e adição de quatro concentrações diferentes (1\%, $5 \%, 10 \%$ e $50 \%$ ) de carne bovina à carne bubalina, totalizando seis tratamentos. $\mathrm{O}$ efeito do processamento térmico sobre a capacidade do método em detectar carne bubalina e carne bovina foi avaliado pela análise de 30 amostras autoclavadas (de búfalos e de bovinos). As repostas, por serem dicotômicas, foram analisadas em uma tabela de frequência pelo teste de qui-quadrado $\left(\chi^{2}\right)$, com nível de significância de 5\%. Para a comparação dos dois métodos de extração, foi utilizado o teste exato de Fisher (Sampaio, 2002).

\section{RESULTADOS E DISCUSSÃO}

A utilização da técnica do fenol/clorofórmio/ álcool-isoamílico, com precipitação e purificação com etanol (Sambrook et al., 1989), apresentou melhor resultado, com diferença significativa quando comparada ao kit comercial EZ-DNA para extração de DNA ( $\mathrm{p}=0,0153)$.

Os resultados das análises das amostras de carne bovina e bubalina, após a digestão com enzimas de restrição HinfI e TaqI, encontram-se na Tabela 1. O teste apresentou alta especificidade, neutralizando o efeito de polimorfismos intraespecíficos com o uso das enzimas de restrição, o que permitiu identificar espécies filogeneticamente próximas, como Bos taurus e Bubalus bubalis. Estes resultados estão de acordo com os observados por Partis et al. (2000); Verkaar et al. (2002); Bellis et al. (2003); Myers, (2003); Girish et al. (2005). 
Tabela 1. Resultados dos testes com amostras de carne bubalina e bovina após a digestão com enzimas de restrição Hinfı e TaqI

\begin{tabular}{cccccc}
\hline Amostra & $\mathrm{n}$ & \multicolumn{4}{c}{ Cortes com enzimas de restrição (\%) } \\
\hline Boi & 30 & 0 & 100 & 100 & 0 \\
Búfalo & 30 & 100 & 0 & 0 & 100 \\
\hline
\end{tabular}

n= número total de amostras.

Os resultados das análises das amostras de carne de búfalo adicionadas de carne bovina encontram-se na Tabela 2. A metodologia utilizada apresentou alta sensibilidade $(\mathrm{P}<0,0001)$ para detectar adições de carne bovina em carne bubalina em concentrações superiores a $10 \%$. A sensibilidade é um parâmetro importante a ser avaliado, pois, quanto mais sensível, maior a capacidade do teste em detectar pequenas porcentagens de adição de carne bovina aos produtos à base de carne bubalina, de forma intencional ou não. A sensibilidade do teste foi comprometida pela dificuldade em se obter uma mistura homogênea das amostras testadas, devido à natureza do material, que é sólido, e não permitiu uma mistura tão homogênea quanto a que se obtém de matérias-primas líquidas. Partis et al. (2000) também observaram diferença na sensibilidade do método e concluíram que o estado sólido da amostra teve efeito negativo sobre esse parâmetro. Desse modo, deve-se estudar outras formas de homogeneização das amostras de modo a contornar esse problema.

Tabela 2. Resultados dos testes em fraudes controladas de carne bovina misturada à carne bubalina, após a digestão com enzimas de restrição $\operatorname{Hinfl}$ e $T a q \mathrm{I}$

\begin{tabular}{cccccc}
\hline Mistura & $\mathrm{n}$ & \multicolumn{5}{c}{ Cortes com enzimas $(\%)$} \\
\hline $1 \%$ & 79 & TaqI positivo & TaqI negativo & Hinf $\mathrm{I}$ positivo & HinfI negativo \\
\hline $5 \%$ & 100 & 0 & 0 & 36,7 & 63,3 \\
$10 \%$ & 100 & 100 & 0 & 29,3 & 70,7 \\
$50 \%$ & 30 & 100 & 0 & 100 & 0 \\
& 30 & & 94 & 6 \\
\hline
\end{tabular}

n= número total de amostras.

A utilização de fragmentos do citocromo $b$ mitocondrial para amplificação de DNA foi adequada, pois o DNA mitocondrial é mais abundante que o genômico, o que levou a um aumento da sensibilidade da técnica. Este resultado está de acordo com os observados por Parson et al. (2000), Herman (2001), LopezCalleja et al. (2005) e Arslam et al. (2006).

Após a digestão com enzima TaqI, o produto de PCR apresentou 108 e 163 pb para a carne bubalina e $271 \mathrm{pb}$ para carne bovina. Já após a digestão com enzima Hinfl, os fragmentos foram de 101 e $170 \mathrm{pb}$ para a carne bovina e $271 \mathrm{pb}$ para a bubalina (Fig. 1). Estes resultados são semelhantes aos observados por Verkaar et al. (2002).
Ao avaliar produtos termicamente processados, foi observado que ocorreu amplificação de DNA, porém apresentando diferença significativa quando comparada ao material in natura $(\mathrm{p}=0,0076)$, possivelmente pelo fato de $\mathrm{o}$ fragmento amplificado ter $271 \mathrm{pb}$. A amplificação de um fragmento relativamente pequeno de DNA viabiliza a aplicação da técnica em produtos termicamente processados, pois o DNA da carne quebra-se em pequenos fragmentos após $\mathrm{o}$ tratamento térmico. Assim sendo, quanto menor o fragmento a ser amplificado, maiores as chances de sucesso da técnica, sendo ideal a utilização de fragmentos menores que 200pb (Partis et al., 2000; Pascoal et al., 2005; Arslam et al., 2006). 


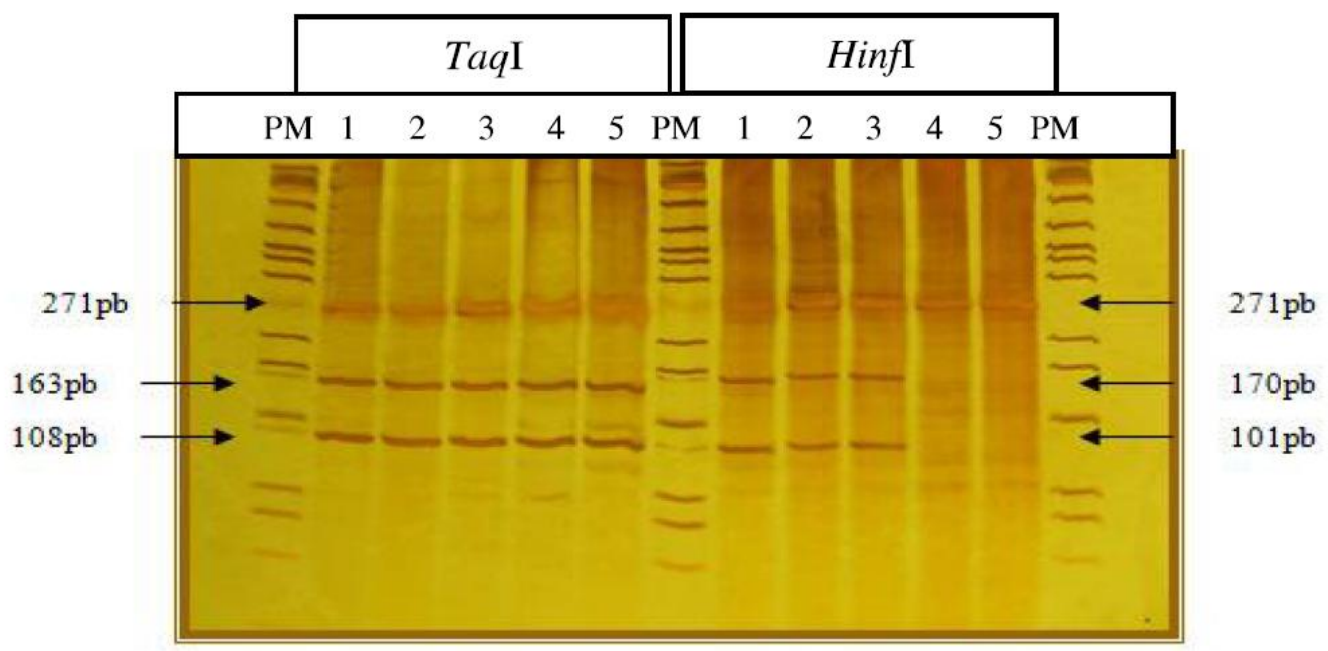

Figura 1. Gel de poliacrilamida a $8 \%$, corado com nitrato de prata. Produto de restrição enzimática com TaqI e HinfI em cinco amostras de carne de búfalo (de 1 a 5 ) adicionadas de $5 \%$ de carne de boi.

\section{CONCLUSÕES}

A técnica de PCR-RFLP tem alta especificidade e, desse modo, pode ser empregada na certificação da identidade e autenticidade de produtos cárneos de origem bubalina e bovina. A metodologia apresenta alta sensibilidade para detectar adições superiores a $10 \%$ de carne bovina em carne bubalina. Além disso, essa técnica detecta sequências de DNA em amostras cárneas autoclavadas, viabilizando sua aplicação em produtos de origem bovina e bubalina processados termicamente.

\section{REFERÊNCIAS}

ARSLAM, A.; ILHAK, O.I.; CALICIOGLU, M. Effect of method of cooking on identification of heat processed beef using polymerase chain reaction (PCR) technique. Meat Sci., v.72, p.326330, 2006.

BALLIN, N.Z.; VOGENSEN, F.K.; KARLSSON, A.H. Species determination - Can we detect and quantify meat adulteration? Meat Sci., v.83, p.165-174, 2009.

BELLIS, C.; ASHTON, K.J.; FRENEY, L. et al. A molecular genetic approach for forensic animal species identification. Forensic Sci. Int., v.134, p.99-103, 2003.

BOTTERO, M.T.; DALMASSO, A. Animal species identification in food products: Evolution of biomolecular methods. Vet. J., v.190, p.34-38, 2010 .
CORONA, B.; LLEONARD, R.; CARPIO, Y. et al. Short communication. PCR detection of DNA of bovine, ovine-caprine and porcine origin in feed as part of a bovine spongiform encephalopathy control program. Spanish $J$. Agric. Res., v.5, p.312-317, 2007.

DAFM - DEPARTMENT of Agriculture Food and the Marine. Equine DNA \& Mislabelling of Processed Beef Investigation, 2013. Disponível em:

http://www.agriculture.gov.ie/media/migration/p ublications/2013/EquineDNAreportMarch20131 90313.pdf. Acessado: 10 abril de 2013.

GIRISH, P.S.; ANJANEYULU, A.S.R.; VISWAS, K.N. et al. Meat species identification by polymerase chain reaction-restriction fragment length polymorphism (PCR-RFLP) of mitochondrial 12S rRNA gene. Meat Sci. v.70, p.107-112, 2005.

GOULI, Z.; MINGGUANG, Z.; ZHIJIANG, Z. et al. Establishment and application of a polymerase chain reaction for the identification of beef. Meat Sci., v.51, p.233-236, 1999.

HERMAN, L. Indetermination of the animal origin of raw food by species-specific PCR. J. Dairy Res., v.68, p.429-439, 2001.

KESMEN, Z.; GULLUCE, A.; SAHIN, F. et al. Identification of meat species by TaqMan based real-time PCR assay. Meat sci., v.82, p.444-449, 2009. 
LOCKLEY, A.K.; BARDSLEY, R.G. DNAbased methods for food authentication. Trends in Food Sci. Techn., v.11, p.67-77, 2000.

LOPEZ-ANDREO, M.; LUGO, L.; GARRIDOPERTIERRA, A. Identification and quantification of species in complex DNA mixtures by realtime polymerase chain reaction. Analytical Biochem., v.339, p.73-82, 2005.

LOPPARELLI, R.M.; CARDAZZO, B.; BALZAN, S. et al. Real-time TaqMan polymerase chain reaction detection and quantification of cow DNA in pure water buffalo Mozzarella cheese: method validation and its application on commercial samples. J. Agric. Food Chem., v.55, p.3429-3434, 2007.

MAYER, H.K. Milk species identification in cheese varieties using electrophoretic chromatographic and PCR techniques. Int. Dairy J., v.15, p.595-604, 2005.

MYERS, M.J.; YANCY, H.F.; FARREL, D.E. Characterization of a polymerase chain reactionbased approach for the simultaneous detection of multiple animal-derived materials in animal feed. J. Food Prot., v.66, p.1085-1089, 2003.

PARSON, W.; PEGORARO, K.; NIEDERSLATTER, F.M. Species identification by means of the cytochromo b gene. I. J. Legal Med., v.114, p.2328, 2000.

PARTIS, L.; CROAN, S.; GUO, Z. et al. Evaluation of a DNA fingerprinting method for determining the species origin of meats. Meat Sci., v.54, p.369-376, 2000.
PASCOAL, A.; PRADO, M.; CALO, P. et al. Detection of bovine DNA in raw and heatprocessed foodstuffs, commercial foods and specific risk materials by a novel specific polymerase chain reaction method. Eur. Food Res. Technol. v.220, p.444-450, 2005.

SAMBROOK, J.; FRITSCH, E.F.; MANIATIS, T. Molecular cloning: a laboratory manual. v.3. 2. ed.New York :Cold Spring Harbor, 1989.

SAMPAIO, I.B.M. Estatística aplicada à experimentação animal. $2^{\mathrm{a}}$ ed. $\quad$ Belo Horizonte:Fundação de Estudo e Pesquisa em Medicina Veterinária, 2002. 265p.

TANABE, S.; MIYAUCHI, E.; MUNESHIGE, A. et al. PCR method of detecting pork in foods for verifying allergen labeling and for identifying hidden pork ingredients in processed foods. BioscBiotechnolbiochem. v.71, p.1663-1667, 2007.

VERKAAR, E.L.C.; NIJMAN, I.J.; BOUTAGA, K.; LENSTRA, J.A. Differentiation of cattle species in beef by PCR-RFLP of mitochondrial and satellite DNA. Meat Sci., v.60, p.365-369, 2002.

ZHANG, C.L.; FOWLER, M.R.; SCOTT, N.W. et al. A taqMan real-time PCR system for the identification and quantification of bovine DNA in meats, milks and cheeses. Food control., v.18, p.1149-1158, 2007. 